\title{
NOTE
}

\section{Comment on Jellett et al. (1989)}

\author{
R. J. Miller \\ Department of Fisheries and Oceans, PO Box 550, Halifax, Nova Scotia, Canada B3J 2S7
}

Jellett et al. (1989) recently published a note on the field occurrence of the pathogenic amoeba responsible for sea urchin mass mortalities in Nova Scotia during the early 1980's. Their conclusions could have benefitted from more thorough research. The following are specific points of concern.

The title ('Non-occurrence of free-living Paramoeba invadens in water and sediments of Halifax Harbour, Nova Scotia, Canada'), the abstract ('Seawater and sediment samples from various sites in or near Halifax Harbour were cultured for Paramoeba. .), and the purpose ('...to determine. if $P$. invadens can be recovered from sediment or seawater. .) all refer to sediment sampling in Halifax Harbour. However, the only sediment sampling mentioned in the methods or results was from an aquarium in the laboratory.

The authors concluded that '... Strongylocentrotus droebachiensis, the natural host for $P$. invadens, do not harbour a reservoir population of this organism at temperatures sub-optimal for paramoebiasis ... This conclusion was based on a single sea urchin sample from one location and date, even though Halifax Harbour has a shoreline length of $90 \mathrm{~km}$ and temperatures are suboptimal for paramoebiasis 8 mo of the year.

The authors maintained diseased sea urchins in a laboratory aquarium for several years. The outfall from this facility empties into an arm of Halifax Harbour. Cages stocked with 50 sea urchins each were placed at the outfall, $1 \mathrm{~km}$ away, and $2 \mathrm{~km}$ away. Paramoeba invadens were recovered from morbid sea urchins from all 3 cages. This result suggested to the authors '... that virulent Paramoeba invadensis released from the Aquatron (aquarium) outfall and can cause disease in the caged sea urchins'. This result would have been more convincing had there been controls to show that the sea urchins were not infected before being stocked and that only sea urchins near the outfall developed infections. Had some of the urchins from the original collection been caged and returned to the collection site, which was far from the outfall, both concerns could have been met.
Another experiment led to the conclusion '...that loss of virulence may occur in Paramoeba released at the Aquatron outfall'. A single amoeba collected in a water sample near the outfall was cultured, and the culture injected into healthy sea urchins. Disease symptoms did not develop and amoebae were not recovered from tissues of injected urchins. One amoeba is an inadequate sample and the results contrast with the presumed transfer of disease from the same source to caged urchins.

The authors' conclusion that Paramoeba invadens was not endemic to the Atlantic coast of Nova Scotia prior to sea urchin mass mortalities during 1980 to 1983 may be correct. However, their sparse sampling during 1987 provides only a modicum of support.

Finally, the authors quoted their publications as authority for the identification of disease symptoms and for the discovery that the agent causing sea urchin mass mortalities was waterborne and could be transferred in the laboratory. Both these results were first obtained elsewhere (Miller \& Colodey 1983, and again in Miller 1985a). Also, there was no mention of a previous experimental transfer of the sea urchin disease from laboratory to field (Miller 1985b), even though this was a result claimed from their caging experiment. Miller \& Colodey (1983), Scheibling \& Stephenson (1984), Jones et al. (1985), and Jones \& Scheibling (1985) were all referenced for identifying Paramoeba invadens as the cause of sea urchin mass mortalities. The only correct source is the last reference.

\section{LITERATURE CITED}

Jellett, J. F., Novitsky, J. A., Cantley, J. A., Scheibling, R. E. (1989). Non-occurrence of free-living Paramoeba invadens in water and sediments of Halifax Harbour, Nova Scotia, Canada Mar. Ecol. Prog. Ser. 56: 205-209

Jones, G. M., Scheibling, R. E. (1985). Paramoeba sp. (Amoebida, Paramoebidae), as the possible causative 
agent of sea urchin mass mortality in Nova Scotia. J Parasitol. 71: 559-565

Jones, G. M., Scheibling, R. E., Hebda, A. J., Miller, R. J. (1985). Amoebae in tissues of diseased echinoids (Strongylocentrotus droebachiensis) in Nova Scotia. In: Keegan, B. F., O'Connor, B. D. S. (eds.) Proc. 5th Int. Echinoderms Conf., 1984. Balkema, Rotterdam, p. 269-293

Miller, R. J. (1985a). Succession in sea urchin and seaweed abundance in Nova Scotia, Canada. Mar. Biol. 84: 275-286
Miller, R. J. (1985b). Sea urchin pathogen: a possible tool for biological control. Mar Ecol. Prog. Ser. 21: $169-174$

Miller, R. J., Colodey, A. G. (1983). Widespread mass mortalities of the green sea urchin in Nova Scotia. Canada, Mar. Biol. 73: 263-267

Scheibling, R. E., Stephenson, R. L. (1984). Mass mortalities of Strongylocentrotus droebachiensis (Echinodermata: Echinoidea) off Nova Scotia. Mar. Biol. 78: 153-164

Manuscript received: November 2,1989 